\section{Wann ist es ein atopisches Ekzem?}

\author{
Epidemiologische Studien zur Prävalenz des atopischen Ekzems bei \\ Kindern haben bisher recht unterschiedliche Ergebnisse geliefert. Ein \\ Grund dafür könnte das Fehlen einheitlicher Diagnosekriterien sein. \\ Dänische Dermatologen gingen dieser Vermutung jetzt nach.
}

든 in Forscherteam untersuchte 562 in der Universitätsklinik Odense geborene Kinder unmittelbar nach der Entbindung sowie nach weiteren 3, 6, 9, 12 und 18 Monaten. Die Prüfärzte versuchten dabei nach den folgenden vier Kriterien ein atopisches Ekzem zu diagnostizieren: nach Hanifin und Rajka, nach Schultz-Larsen, nach eigens für die Studie entwickelten Kriterien des Danish Allergy Research Centre und nach ihrer subjektiven Beurteilung aufgrund des klinischen Erscheinungsbilds. Im Alter von einem Jahr wurde zusätzlich ein in Großbritannien gebräuchlicher Fragebogen herangezogen.

Je nach eingesetztem diagnostischen Vorgehen ergaben sich folgende kumulative 1-Jahres-Prävalenzen: 9,8\% nach
Hanifin und Rajka, 7,5\% nach SchultzLarsen, 8,2\% nach den Kriterien des Danish Allergy Research Centre, 12,2\% nach dem klinischen Erscheinungsbild sowie 7,5\% nach Anwendung des britischen Fragebogens. Im paarweisen Vergleich stimmten die Diagnosekriterien im Allgemeinen gut überein, Abweichungen ergaben sich vor allem bei Kindern mit nur sehr geringer Krankheitsmanifestation. Die Übereinstimmung zwischen den vier Kriterien war zudem für die kumulative Prävalenz nach einem Jahr höher als für die Prävalenzen zu den einzelnen Untersuchungszeitpunkten.

Fazit: Verschiedene Kriterien zur Diagnose eines atopischen Ekzems bei Kleinkindern liefern letztlich vergleich-

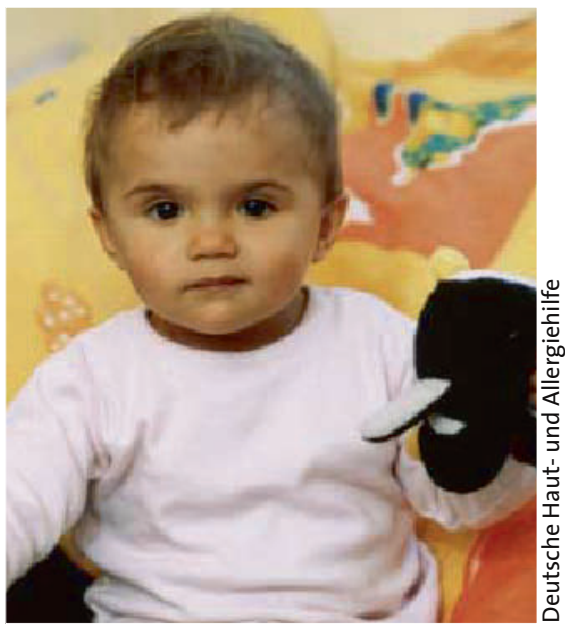

Nur etwas gerötete Wangen oder schon ein beginnendes atopisches Ekzem? Die Diagnose ist nicht immer einfach.

bare Prävalenzdaten. Problematisch ist die Zuordnung bei klinisch nur wenig ausgeprägten Symptomen.

Jøhnke $\mathrm{H}$ et al. A comparison between criteria for diagnosing atopic eczema in infants. Br J Dermatol 2005; 153: 352-58

\title{
Angsthase Atopiker
}

Psychische Belastungen können bei Patienten mit atopischer Dermatitis das Hautbild verschlechtern. Welche Rolle dabei Angstzuständen als einer wichtigen Ursache von psychischem Stress zukommt, hat jetzt eine Studie untersucht.

D ermatologen der Universitätsklinik Hamamatsu, Japan, bezogen 85 Patienten mit einer atopischen Dermatitis nach den Kriterien von Hanifin und Rajka sowie 58 Kontrollpersonen ohne Anamnese einer allergologischen Erkrankung in ihre Untersuchung ein. Die Probanden wurden anhand des State-Trait Anxiety Inventory (STAI) untersucht. Dieser Selbstbeurteilungsbogen erlaubt Aussagen über das Ausmaß der „trait anxiety" - Angst als grundlegendes Persönlichkeitsmerkmal - im Vergleich zur „state anxiety“ - situative Angstzustände, die nur momentan oder in bestimmten Situationen auftreten. In der Patientengruppe wurden zusätzlich allergologische Blutparameter bestimmt.
Insgesamt war das Merkmal Angst bei den Patienten mit atopischer Dermatitis ausgeprägter als bei den Kontrollpersonen. Zudem dominierte bei ihnen die „trait anxiety“ über die „state anxiety“. Das Gesamt-IgE im Serum der Patienten korrelierte positiv mit der "trait anxiety“ und dem Quotienten aus "trait anxiety“ und ,state anxiety" sowie invers mit der „state anxiety“. Das Verhältnis von TH1zu TH2-Helfer-Zellen korrelierte invers mit der ,trait anxiety" bzw. dem Verhältnis von "trait anxiety“ zu „state anxiety“.

Damit scheint Ängstlichkeit als Charaktereigenschaft stärker mit immunologischen Parametern der Atopie verknüpft zu sein als situative Angst. Erklärt werden könnte dieser Zusammenhang über psy- chischen bzw. physischen Stress: Patienten mit erhöhten IgE-Werten sind leichter erregbar und können mit Stresssituationen insgesamt schlechter umgehen. Akuter Stress wiederum lässt die SerumIgE-Werte steigen und induziert einen TH1-/TH2-Switch. Vermittelt werden diese Effekte durch die Aktivierung der Hypothalamus-Hypophysen-Nebennierenrinden-Achse und die dadurch induzierte Freisetzung von Glukokortikoiden sowie die Aktivierung des sympathischen Nervensystems. Auf die Schwere der Hauterscheinungen hat Angst aber nicht unbedingt einen Einfluss.

Fazit: Bei Patienten mit atopischer Dermatitis korreliert eine ausgeprägte Ängstlichkeit als Persönlichkeitsmerkmal mit erhöhten IgE-Werten und einem niedrigen TH1-/TH2-Verhältnis

\section{$b k$}

Hashizume $\mathrm{H}$ et al. Anxiety accelerates T-helper 2-tilted immune responses in patients with atopic dermatitis. Br J Dermatol 2005; 152: 1161-4 